\title{
Mumps Orchitis: Clinical Aspects and Mechanisms
}

\author{
Han Wu ${ }^{1,2}$, Fei Wang ${ }^{2}$, Dongdong Tang ${ }^{3}$ and Daishu $\mathrm{Han}^{2 *}$ \\ 1 Department of Immunology, Shenzhen University School of Medicine, Shenzhen, China, 2 Institute of Basic Medical \\ Sciences, School of Basic Medicine, Peking Union Medical College, Chinese Academy of Medical Sciences, Beijing, China, \\ ${ }^{3}$ Reproductive Medicine Center, Department of Obstetrics and Gynecology, The First Affiliated Hospital of Anhui Medical \\ University, Hefei, China
}

The causative agent of mumps is a single-stranded, non-segmented, negative sense RNA virus belonging to the Paramyxoviridae family. Besides the classic symptom of painfully swollen parotid salivary glands (parotitis) in mumps virus (MuV)-infected men, orchitis is the most common form of extra-salivary gland inflammation. Mumps orchitis frequently occurs in young adult men, and leads to pain and swelling of the testis. The administration of MuV vaccines in children has been proven highly effective in reducing the incidence of mumps. However, a recent global outbreak of mumps and the high rate of orchitis have recently been considered as threats to male fertility. The pathogenesis of mumps orchitis remains largely unclear due to lack of systematic clinical data analysis and animal models studies. The alarming increase in the incidence of mumps orchitis and the high risk of the male fertility have thus become a major health concern. Recent studies have revealed the mechanisms by which MuV-host cells interact and MuV infection induces inflammatory responses in testicular cells. In this mini-review, we highlight advances in our knowledge of the clinical aspects and possible mechanisms of mumps orchitis.

Keywords: mumps, MuV, orchitis, testis, infertility

\section{INTRODUCTION}

Mumps is a worldwide contagious disease caused by mumsp virus $(\mathrm{MuV}) . \mathrm{MuV}$ is mainly transmitted via the respiratory route. $\mathrm{MuV}$ infection results in painful inflammatory symptoms, such as parotitis, orchitis, oophoritis, aseptic meningitis, encephalitis and pancreatitis (1). Besides the typical painfully swollen parotitis in infected males, orchitis is the most common extra-salivary inflammation and an important etiological factor of male infertility (2).

Mumps orchitis generally manifests around a week after the onset of parotitis $(1,3)$. Approximately $30 \%$ of mumps orchitis in post pubertal males suffer from infertility or subfertility (3). Mumps orchitis may lead to the atrophy of germinal epithelium with spermatogenesis arrest and the disruption of steroidogenesis. MuV complications are not lethal, therefore lacking human samples to examine disease pathogenesis.

Current information on pathogenesis after $\mathrm{MuV}$ infection is largely based on investigation using animal models (4-8). We have recently examined mechanisms underlying MuV infection of testicular cells, MuV-induced immune responses and impairment of testicular functions in mouse 
models, which provide novel insights into the pathology of mumps orchitis and related male infertility (9-11). In this mini review, we briefly summarize $\mathrm{MuV}$ biology and focus on mechanisms underlying pathogenesis of mumps orchitis.

\section{MUV AND COMPLICATIONS}

MuV belongs to the Paramyxoviridae family, which consists of enveloped particles that contain a non-segmented single negative-strand RNA genome (Figure 1). The MuV genome consists 15,384 nucleotides that encodes seven proteins: nucleoprotein (NP), polymerase (L), phosphoprotein $(\mathrm{P})$, matrix protein $(\mathrm{M})$, hemagglutinin/neuraminidase $(\mathrm{HN})$, fusion protein $(\mathrm{F})$, and small hydrophobic protein $(\mathrm{SH})(12)$. $\mathrm{MuV}$ strains can be classified into 12 genotypes based on the nucleotide diversity of the $\mathrm{SH}$ gene $(13,14)$. Viral RNA encapsulated by NP is the template for replication. A complex of $\mathrm{L}$ and $\mathrm{P}$ acts as a replicase to transform the negative-strand RNA to a positive-strand RNA and as a transcriptase to generate mRNA. HN and F glycoproteins cooperatively mediate virus attachment and internalization to host cells via its receptor sialic acid that is present on the surface of most mammalian cell types.

$\mathrm{MuV}$ is initially transmitted via the respiratory route by the inhalation of contaminated droplets from an infected respiratory tract. Based on the array of symptoms, MuV would initially replicate within the lymphoid and reticuloendothelial tissue of the respiratory tract, which then lead to a transient viremia that may spread viruses into multiple organs (12). While it is assumed that $\mathrm{MuV}$ first infects the respiratory epithelium, the primary target cells for early infection and replication remain unclear. However, $\mathrm{MuV}$ has rarely been detected in blood, probably due to the coincident development of specific antibodies.

Besides asymptomatic and mild respiratory diseases in approximately $30 \%$ of infections, the typical characteristics of mumps include swollen parotitis, which is used to diagnose the disease. Parotid gland swelling is mostly bilateral, occurs 2-3 weeks after transmission, and lasts for 2-3 days. The symptom may persist for a week or more in minor cases. Following parotitis, $\mathrm{MuV}$ infection can lead to inflammation in the reproductive and central nerve systems, including orchitis, oophoritis, encephalitis, and meningitis (1). MuV may also result in myocarditis, pancreatitis and nephritis. While the complications are mostly self-limiting, long-term sequelae such as infertility, paralysis, hydrocephalus and deafness can occur. Mumps orchitis is the most concerned extra-parotid gland inflammation due to its detrimental effect on human reproduction.

\section{CLINICAL ASPECTS OF MUMPS ORCHITIS}

\section{Vaccination and Incidences of Mumps Orchitis}

In the pre-vaccine era, mumps was an infectious disease that was most commonly transmitted among children and was mainly

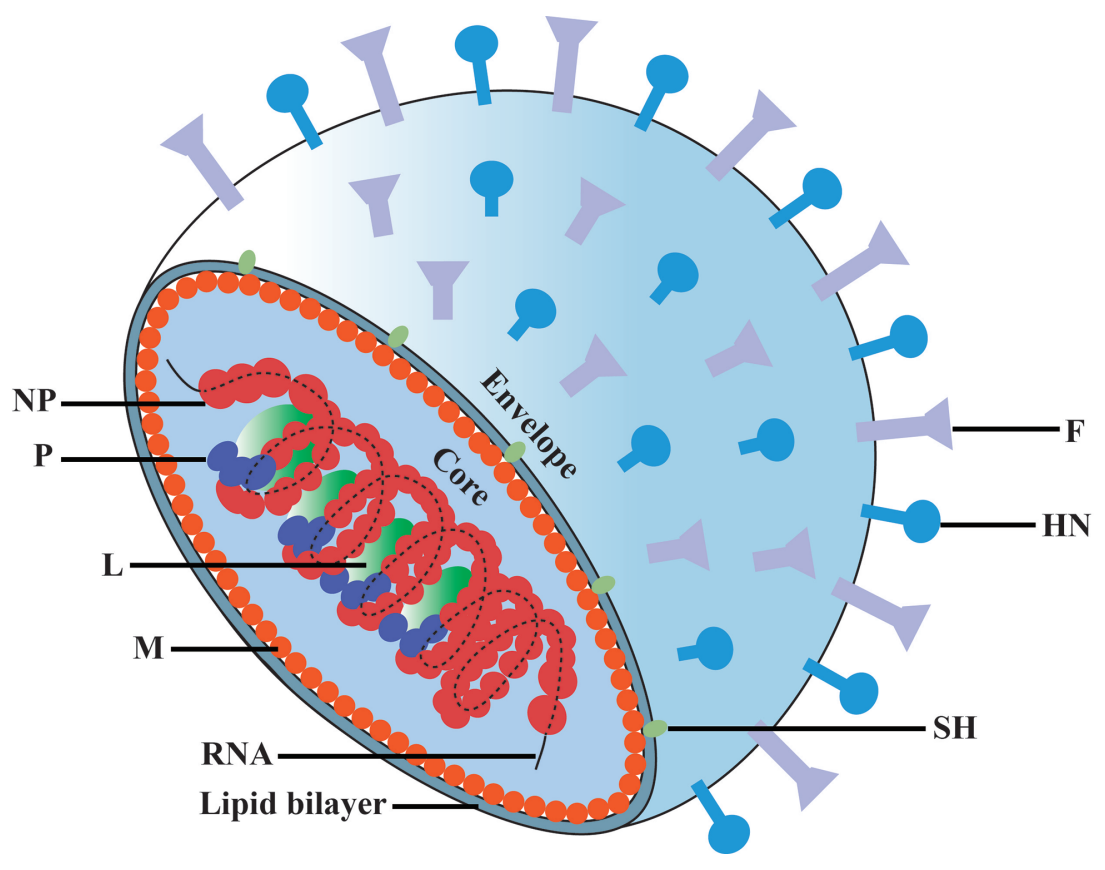

FIGURE 1 | Schematic diagram of mumps virus. The MuV core is enveloped by matrix protein (M) and lipid bilayer containing small hydrophobic protein (SH), spike fusion protein $(F)$ and hemagglutinin-neuramindase $(H N)$. The genomic RNA combines with nucleoprotein (NP), polymerase (L) and phosphoprotein $(P)$ to form the core of the helical nucleocapsid. 
complicated with parotitis $(15,16)$. With routine $\mathrm{MuV}$ vaccination, mumps incidence has dramatically declined. However, there have been large outbreaks of mumps worldwide in the past decades, including vaccinated populations (17-31). In China, the mumps vaccine was first introduced in the National Immunization Program in 2007 (32). From June 2020, the policy had changed to receive two doses of trivalent measles, mumps and rubella (MMR) vaccine. The annual occurrence of mumps cases from 2009 to 2019 is shown in Figure 2. After high vaccination coverage, mumps incidence dropped by half in 2016 from its peak in 2012. Notably, mumps incidences slightly increased from 2017 to 2019 . This may be due to the fact that more than 10 years have passed since the first one dose vaccine was administered, and vaccine effectiveness has declined.

The recent resurgence of mumps mainly involved adolescents and young adults, with high rates of orchitis frequently reported $(3,33-35)$. Orchitis is the most common complication of mumps and occurs in as high as $40 \%$ of all mumps cases in young adult men (36). Mumps orchitis is mostly unilateral, but can occur bilaterally in $10-30 \%$ of cases (37). Unvaccinated postpubertal males are susceptible to virus outbreaks and are at high risk of developing mumps orchitis. In China, the vaccination rate of men born in the 1990s, who are now 30 years old, is low due to lacking MMR vaccination program in less developed areas. Thus, it is essential to be aware of this epidemiological shift and the resurgence of mumps orchitis in the clinic. Cases of orchitis following MMR vaccination are reported in post-pubertal adults, suggesting that the MMR vaccination may have an adverse effect on the testis in certain young adults (38-41). Therefore, whether unvaccinated male in this age group should be offered the MMR vaccine requires in-depth and carefully evaluation.

\section{Clinical Manifestations}

Mumps orchitis usually occurs at about one week after the onset of parotitis in young adult males with $\mathrm{MuV}$ infection. The onset of orchitis is associated with constitutional symptoms, such as headache and fever and later manifests as testicular swollen and pain. Examination of the scrotum generally indicates swelling testes, associated tenderness, and inflammation of the scrotum.
Epididymitis also occurs in most of the mumps orchitis cases and results in mumps epididymo-orchitis $(42,43)$. A recent study demonstrates that the epididymal head is mostly involved in mumps epididymo-orchitis, which is in contrast to bacterial epididymitis that commonly occurs in the cauda epididymis $(44,45)$. During the acute phase, the endocrine function of the testes is altered, e.g., decreased testosterone levels. Some cases also show increased luteinizing hormone (LH) and folliclestimulating hormone (FSH) levels (46). The acute symptoms can resolve within two weeks; however, testicular atrophy can occur in half of the orchitis patients and is characterized by an oblong shape, low echogenicity, and decreased vascularity based on ultrasonographic findings $(3,47)$. However, seminal abnormalities, including sperm count, motility and morphology, may sustain for years after recovery (37), suggesting the abnormal spermatogenesis can occur.

\section{Diagnostic and Therapeutic Approaches}

There is no standard criteria procedure for $\mathrm{MuV}$ diagnosis because it is not a common condition that is observed in hospital. Diagnosis of $\mathrm{MuV}$ is mainly based on clinical complication and laboratory testing. Orchitis characteristically presents with swollen and pain testes. Ultrasonography can provide image features, including low echogenicity, hypervascularity, and increased volume of the testes and epididymis $(43,48)$. Testicular inflammation and hydrocele could also be detected. The routine urine analysis is necessary for diagnosing the mumps orchitis to rule out bacterial infection (33).

The definitive diagnosis of mumps orchitis should be based on laboratory tests. The presence of $\mathrm{MuV}$ in saliva or seminal fluid can be determined by real time RT-PCR. The MuV-specific IgM and IgG antibodies in blood can be measured by ELISA for serological markers of $\mathrm{MuV}$ infection. A positive serum IgM or a four-fold increase in IgG level is considered serologically positive for $\mathrm{MuV}$ infection (49). While $\mathrm{MuV}$ can be isolated from the seminal fluid within two weeks after symptom onset (50), the test for viral infectivity is usually not performed in the clinical diagnosis due to the complicated procedure for this test.

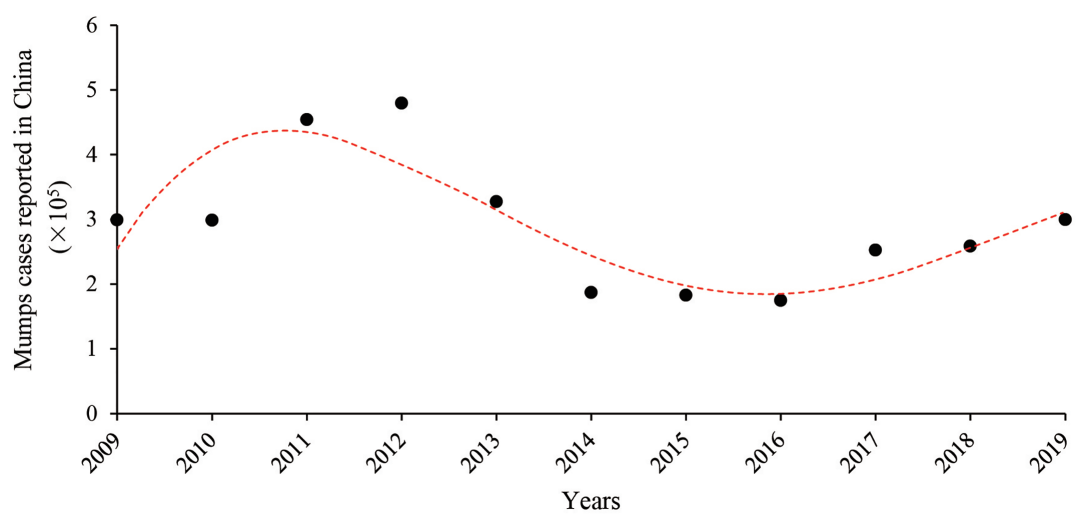

FIGURE 2 | Annual mumps cases reported in China from 2009 to 2019. Data come from reports of the National Health Commission of China. 
$\mathrm{MuV}$ infection is mostly self-limiting, and there is currently no specific antiviral therapy available. The treatment for mumps orchitis generally includes supportive procedures, including bed rest, scrotal support, and analgesic and anti-inflammatory drugs against pain and fever. Symptoms can resolve with treatment in 4-10 days (51). Steroid drugs were used to diminish testicular pain and swelling, but it does not alter the clinical course and prevent subsequent atrophy. Interferon has been used in a series of cases to cure mumps orchitis; however, this is a controversial method because there is conflicting evidence on its therapeutic effect. Erpenbach et al. claimed to have prevented testicular damage and infertility in four patients who had bilateral mumps orchitis by using systematic interferon for seven days (52). However, Yeniyol et al. found that interferon is not effective in preventing testicular atrophy because $40 \%$ of patients presents evidence of total atrophy of seminiferous tubules on testicular biopsies performed during follow-up (53). A recent study that assessed a series of 56 cases of mumps orchitis treated with interferon also showed some kind of hormone or sperm impairment in most patients during the later follow up period, while only two patients (14\%) were considered free of sequelae (3). Although some treatments can diminish the complications of acute mumps orchitis, the preventive and therapeutic approaches of the orchitis-caused testicular damage and subfertility/infertility require establishment.

\section{MECHANISMS OF MUMPS ORCHITIS}

It is difficult to study the pathogenesis of mumps orchitis in humans due to the lack of samples. Recent studies using mouse models provide insights to mechanisms by which $\mathrm{MuV}$ infects testicular cells and impairs testicular functions (Figure 3).

\section{MuV Receptors and Testis Tropism}

It is well-known that $\mathrm{MuV}$ has high tropism to the testis (57). Thus, understanding the mechanism of receptor recognition by $\mathrm{MuV}$ is very important. Sialic acid, which is expressed on the cell surface as a terminal component of sugar chains, plays a role in mediating infection of many viruses, including influenza viruses (58), the Middle East respiratory syndrome coronavirus (59), and Zika virus (ZIKV) (60). A previous study demonstrated that MuV used a trisaccharide containing $\alpha 2,3$-linked sialic acid on the cell surface as a receptor that interacts with $\mathrm{MuV}$ attachment protein $\mathrm{HN}$ (61). The MuV-HN-receptor interaction triggers the activation of the $\mathrm{F}$ protein, causing fusion of the viral envelope with the plasma membrane and allowing cell entry (62). A very recent study has confirmed the presence of sialic acid on the surface of Sertoli cells (SCs) and Leydig cells (LCs) (63). Depletion of sialic acid by sialidase decreases $\mathrm{MuV}$ internalization into SCs and LCs, but does not affect $\mathrm{MuV}$ binding to these cells (63). These results suggest that other coreceptors for $\mathrm{MuV}$ binding to testicular cells exist. Recently, two novel glycan motifs, sialyl Lewis ${ }^{\mathrm{X}}$ (SLe ${ }^{\mathrm{X}}$ ) and the GM2 ganglioside (GM2-glycan), have been shown to serve as MuV receptors (64). Whether these receptors function for $\mathrm{MuV}$ tropism toward testicular cells requires further investigation.
Other types of cell receptors such as AXL and MER, which are members of a subfamily of receptor tyrosine kinases, have been suggested as potential candidates for $\mathrm{MuV}$ tropism. AXL and MER are abundantly expressed in SCs and LCs and play important roles in regulating testicular immune privilege (65). Both AXL and MER can interact with the ligands Gas6 and protein $S$ that in turn bind to the surface of enveloped viruses (66). Several studies have demonstrated that AXL facilitates infection of multiple viruses, including Ebola virus (67), influenza virus (68), and ZIKV (69). AXL and MER have been suggested to function as binding or entry factors for $\mathrm{MuV}$ based on the observation that these are highly expressed in the testis during $\mathrm{MuV}$ infection $(63,70)$. Knockout of $A x l, M e r$, and both $A x l$ and Mer did not affect MuV binding to SCs and LCs, and the levels of $\mathrm{MuV}$ internalized into SCs and LCs were comparable (63). Thus, AXL and MER were not required as binding or entry factors for $\mathrm{MuV}$ in these cells. However, a genetic study showed that double knockout of both $A x l$ and Mer remarkably decreased $\mathrm{MuV}$ replication, whereas single knockout of either Axl or Mer barely affected $\mathrm{MuV}$ replication. Additionally, a study using an inhibitor of AXL and MER showed no change in $\mathrm{MuV}$ replication in type 1 interferon receptor knockout (Ifnar $1^{-/-}$) SCs and LCs, while it significantly decreased in wild-type cells, suggesting a redundant role of AXL and MER in facilitating MuV replication in SCs and LCs by inhibiting the antiviral IFN signaling (63). These findings on the mechanism underlying receptors-mediated $\mathrm{MuV}$ binding, internalization and replication (Figure 3) may be helpful discovering the targets for the prevention of $\mathrm{MuV}$ infection.

\section{MuV-Induced Immune Response in Testicular Cells}

Due to the lack of testicular biopsy from mumps orchitis patients, it is difficult to investigate $\mathrm{MuV}$ infection and pathogenesis in the testis. Although humans are believed to be the only natural reservoir, $\mathrm{MuV}$ was experimentally used to infect various animal models to evaluate protective immunity against $\mathrm{MuV}(8,71)$. Unfortunately, studies on the pathogenesis of orchitis in the animal models are limited. A current study found that $\mathrm{MuV}$ can infect the majority of mouse testicular cells, including SCs, LCs, testicular macrophages (TMs), and male germ cells (GCs) (9). However, MuV differentially replicates in these testicular cells. MuV replicated at relatively high efficiency rate in SCs compared with LCs and TMs. In contrast, MuV does not replicate in male GCs. These findings suggest that testicular cells exhibit different innate antiviral responses against $\mathrm{MuV}$ replication.

To understand the mechanisms underlying $\mathrm{MuV}$-induced orchitis, a recent study investigated the pattern recognition receptors-initiated innate immune responses of testicular cells to $\mathrm{MuV}$ infection (11). $\mathrm{MuV}$ induces innate immune responses in mouse SCs and LCs through the activation of Toll-like receptor 2 (TLR2) and retinoic acid-inducible gene I (RIG-I) signaling pathways. MuV-initiated TLR2 signaling mainly induces pro-inflammatory cytokines (TNF- $\alpha$ and IL-6) as well as chemokines (MCP-1 and CXCL10), whereas the RIG-I 


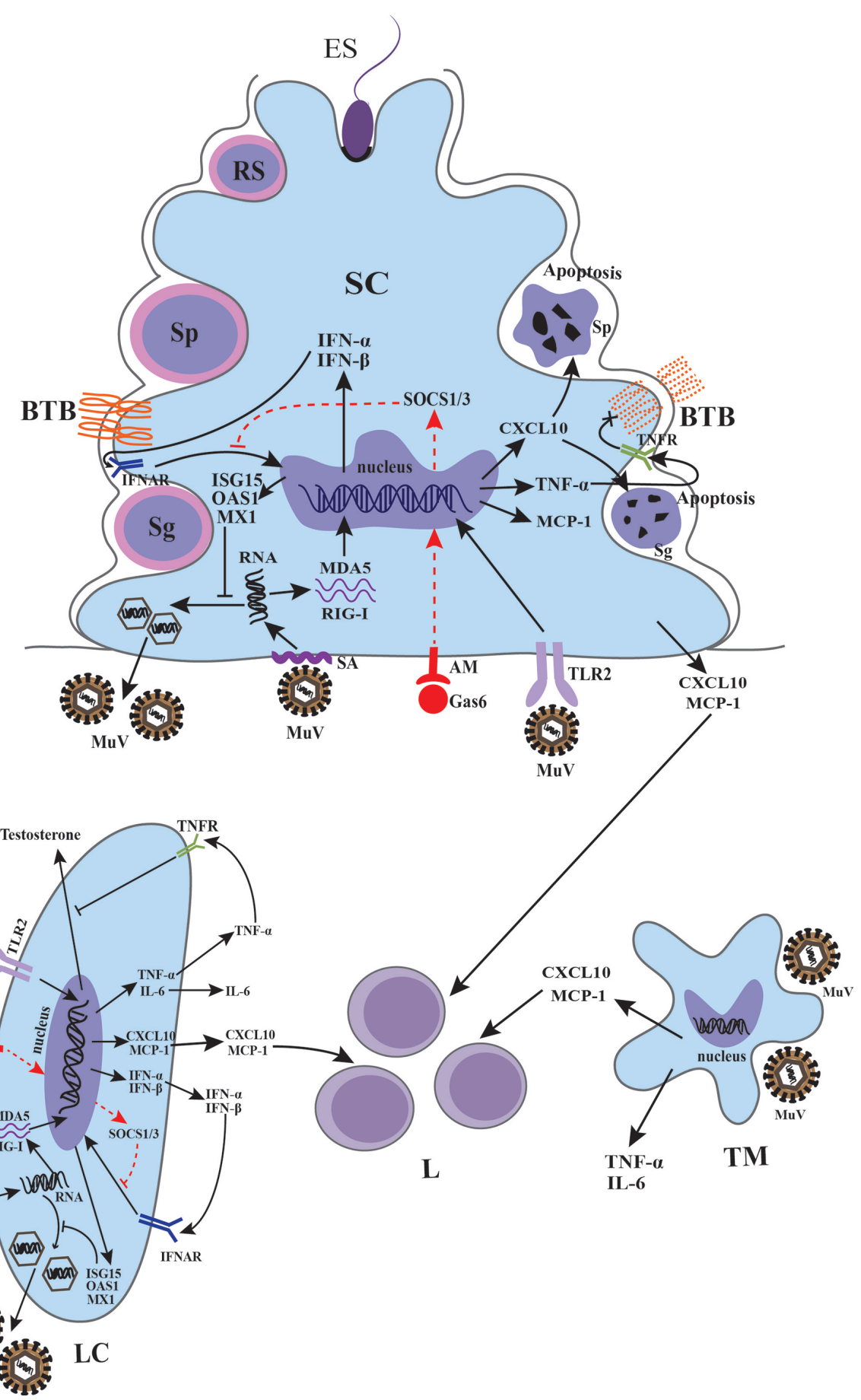

FIGURE 3 | Schematic of MuV infection of testicular somatic cells and downstream effects. Sialic acid (SA) on the surface of Sertoli cells (SCs) and Leydig cells (LCs) mediated MuV entry into cells. Gas6 and Ax//Mer (AM) receptor tyrosine kinase system facilitates MuV replication by inhibiting antiviral response. MuV triggers Toll-like receptor 2 (TLR2) and cytosolic RNA sensors MDA5/RIG-I signaling pathways, thereby inducing the expression of various immunoregulatory cytokines, including pro-inflammatory factors TNF- $\alpha$ and IL-6, chemokines CXCL10 and MCP- 1 , and type 1 interferons INF- $\alpha$ and IFN- $\beta$. IFN- $\alpha$ and IFN- $\beta$ then induce the expression of various proteins, including ISG15, OAS1 and Mx1, that can inhibit MuV replication. MuV infection also induces the production of CXCL10, MCP-1, TNF- $\alpha$ and IL-6 by testicular macrophages (TM). CXCL10 produced by SC in response to MuV infection induces apoptosis of germ cells, whereas TNF- $\alpha$ disrupts blood-testis barrier (BTB) integrity and permeability. MuV infection of LC inhibits testosterone synthesis. MuV-induced TNF- $\alpha$ is presumably responsible for the MuV inhibition of testosterone synthesis. MCP-1 and CXCL10 produced by SC, LC and TM may recruit leukocytes (L), resulting in orchitis. Sg, spermatogonium; Sp, spermatocyte; RS, round spermatid; ES, elongated spermatid. SOCS, suppressor of cytokine signaling. $\rightarrow$, promotion; $\perp$, inhibition; $\times$, disruption of BTB. The red dashed line indicates a possible signaling pathway in SCs and LCs according to previous findings (54-56). 
pathway principally participated in the induction of type 1 interferons (IFN- $\alpha$ and IFN- $\beta$ ). In response to $\mathrm{MuV}$ infection, SCs produced relatively high levels of pro-inflammatory cytokines and chemokines, but low levels of IFN- $\alpha$ and IFN- $\beta$ compared to LCs. A previous study using a mouse model showed that mumps-associated gene geranylgeranyl diphosphate synthase 1 deficiency in SCs resulted in male infertility and abnormal activation of MAPK and NF- $\mathrm{KB}$ downstream of TLR2 signaling (72). These investigations suggest that TLR2 plays a crucial role in initiating the innate immune responses to $\mathrm{MuV}$ infection in testicular cells. However, the TLR2 ligand in $\mathrm{MuV}$ has yet to be identified. In contrast, TNF- $\alpha$, IL-6, MCP-1, CXCL10, IFN- $\alpha$ and IFN- $\beta$ were nearly undetectable in male GCs after $\mathrm{MuV}$ infection, suggesting a low level of innate immune response in GCs (11). MCP-1 and CXCL10 produced by $\mathrm{TMs}$, SCs and LCs in response to $\mathrm{MuV}$ infection should facilitate the recruitment of leukocytes into the testis for $\mathrm{MuV}$ orchitis (Figure 3).

Usually, viral replication in infected cells is restricted by cellular innate antiviral responses. The production of IFNs is a universal mechanism of the host's defense against viral infection (73). IFN- $\beta$ can inhibit MuV replication in SCs, LCs, and TMs by inducing the expression of antiviral proteins, including ISG15, OAS1, and MX1, but not in GCs. Remarkably, GCs and TMs are equipped with autophagy machineries, and autophagy restricts $\mathrm{MuV}$ replication in these cells. In contrast, autophagy is not involved in limiting $\mathrm{MuV}$ replication in LCs and SCs. These findings suggest a cell type-specific innate antiviral mechanisms against $\mathrm{MuV}$ replication in testicular cells.

Notably, viral infection in male GCs may be sexually transmitted to female partners and fetus, thus leading to virus parallel and vertical transmission (74). The antiviral defense of male GCs is particularly important not only for male fertility but also for limiting virus transmission. The innate antiviral responses in most type of cells after viral infection produce type 1 IFNs and various pro-inflammatory cytokines (75). The increased levels of certain pro-inflammatory cytokines can be harmful to spermatogenesis (76). However, autophagy directly uptakes and degrades viruses that invade GCs, without the induction of pro-inflammatory cytokines (77). Therefore, autophagy of male GCs should be suitable for the antiviral defense without harming spermatogenesis.

\section{MuV Infection Damages Testis Function}

The cytokines induced by viral infection can mediate organ dysfunction and tissue damage (78). We recently found that $\mathrm{MuV}$ infection induced the production of various proinflammatory cytokines and inhibited testosterone synthesis in LCs (11). The production of pro-inflammatory cytokines such as TNF- $\alpha$ by LCs after MuV infection may be responsible for the inhibition of testosterone synthesis by reducing the expression of enzymes for testosterone synthesis (79). However, one study showed that the testicular testosterone level was reduced in TNF$\alpha$ knockout mice, which was probably caused by the augmentation of Mullerian inhibiting substance in the testis (80). TNF- $\alpha$ may play dual roles in the protection and disruption of the tissue functions dependent on its level under pathophysiological conditions. The high level of TNF- $\alpha$ in the testis due to infection and inflammation disrupts testicular functions $(81,82)$. Moreover, we demonstrated that the production of TNF- $\alpha$ and CXCL10 in SCs after MuV infection impaired blood-testis barrier (BTB) and induced GC apoptosis, respectively $(10,83)$. The $\mathrm{BTB}$ plays an important role in maintaining normal spermatogenesis. TNF- $\alpha$ produced by SCs in response to $\mathrm{MuV}$ infection impaired $\mathrm{BTB}$ formation by reducing the levels of occludin and zonula occludens 1 (ZO-1) (83). The finding is supported by a previous study that occludin is one of the target proteins of TNF- $\alpha$ in rat SCs (84). Moreover, a recent study showed that the exposure of SCs to inflammatory mediators derived from $\mathrm{ZIKV}$-infected macrophages also led to the degradation of the ZO-1 protein, which correlated with increased BTB permeability (85). These findings suggest an adverse role of virus-induced production of inflammatory cytokines such as TNF- $\alpha$. During spermatogenesis, a large number of novel antigens are produced by post-meiotic spermatids in seminiferous tubules after immune self-tolerance has been established (86). The production of autoantibodies against GC antigens is a common feature for orchitis patients. This may explain why mumps orchitis often causes male infertility in postpubertal and young adult men but rarely affects children when the spermatids have not yet been produced in the testes.

The deleterious effects of $\mathrm{MuV}$ infection on male GCs have also been examined in a recent study (10). The study showed that TNF- $\alpha$ produced by mouse SCs in response to $\mathrm{MuV}$ induced CXCL10 expression in autocrine manner. CXCL10 is a pleiotropic cytokine capable of exerting various functions, including the chemotaxis of leucocytes and induction of apoptosis (87). CXCR3, as the receptor of CXCL10, is expressed on the surface of male GCs. CXCL10 activates caspase-8/3 through CXCR3 that in turn induces GC apoptosis (10). Therefore, blocking CXCL10-CXCR3 signaling may alleviate $\mathrm{GC}$ degeneration caused by $\mathrm{MuV}$ infection.

Laboratory animal models are critical for the studies on the pathogenesis of $\mathrm{MuV}$-induced diseases. Unfortunately, mice are not susceptible to $\mathrm{MuV}$ infection. Although $\mathrm{MuV}$ efficiently replicates in mouse testicular cells in vitro, this is not evident in vivo (11). The detrimental effects of ZIKV on the testis are only occurred in mice lacking interferon signaling but not in WT mice (88). A recent study showed that mice lacking type 1 interferon signaling were susceptible to $\mathrm{MuV}$ infection (71). Whether orchitis is generated in Ifnar $^{-1-}$ mice after $\mathrm{MuV}$ inoculation remain unknown, and thus requires further investigation. Alternatively, a mouse cell-adapted $\mathrm{MuV}$ strain may be used to establish an orchitis model, but how far the observations in mouse models are relevant to human remains questionable.

\section{CONCLUSIONS}

The recent outbreaks occurring in highly vaccinated populations have sparked renewed interest in mumps and complications, particularly orchitis. There is a growing concern that a group of 
mumps cases has shifted from children to young adults and is associated with a high rate of orchitis and severe reproductive problems. The mechanisms behind the development of mumps and orchitis are unknown. Several recent studies on $\mathrm{MuV}$ based on primary cells have improved our understanding of mumps virus pathogenesis with regard to $\mathrm{MuV}$ receptors-testicular cells interaction, innate immune responses to $\mathrm{MuV}$ infection, and detrimental effects on testicular function using mouse models. However, a number of knowledge gaps remain. $\mathrm{MuV}$ can effectively replicate in mouse testicular cells in vitro. The testis is an immunoprivileged organ for the protection of the spermatozoon from adverse immune response (89). Whether the testicular immune privilege status provides a refuge for $\mathrm{MuV}$ replication to escape immune surveillance requires clarification. Rare orchitis cases after the MMR vaccination were reported, suggesting a potential risk of the vaccination $(38-41,71)$. The pathogenesis of the vaccination-related orchitis remains uncertain and is worth investigating further. In-depth

\section{REFERENCES}

1. Hviid A, Rubin S, Mühlemann K. Mumps. Lancet (2008) 371:932-44. doi: 10.1016/s0140-6736(08)60419-5

2. Masarani M, Wazait H, Dinneen M. Mumps orchitis. J R Soc Med (2006) 99:573-5. doi: 10.1258/jrsm.99.11.573

3. Ternavasio-de la Vega HG, Boronat M, Ojeda A, Garcia-Delgado Y, AngelMoreno A, Carranza-Rodriguez C, et al. Mumps orchitis in the post-vaccine era (1967-2009): a single-center series of 67 patients and review of clinical outcome and trends. Med (Baltimore) (2010) 89:96-116. doi: 10.1097/ MD.0b013e3181d63191

4. Rozina EE, Hilgenfeldt M. Comparative study on the neurovirulence of different vaccine strains of parotitis virus in monkeys. Acta Virol (1985) 29:225-30.

5. McCarthy M, Jubelt B, Fay DB, Johnson RT. Comparative studies of five strains of mumps virus in vitro and in neonatal hamsters: evaluation of growth, cytopathogenicity, and neurovirulence. J Med Virol (1980) 5:1-15. doi: 10.1002/jmv.1890050102

6. Kilham L, Margolis G. Induction of congenital hydrocephalus in hamsters with attenuated and natural strains of mumps virus. J Infect Dis (1975) 132:462-6. doi: 10.1093/infdis/132.4.462

7. Parker L, Gilliland SM, Minor P, Schepelmann S. Assessment of the ferret as an in vivo model for mumps virus infection. J Gen Virol (2013) 94:1200-5. doi: 10.1099/vir.0.052449-0

8. Xu P, Huang Z, Gao X, Michel FJ, Hirsch G, Hogan RJ, et al. Infection of mice, ferrets, and rhesus macaques with a clinical mumps virus isolate. $J$ Virol (2013) 87:8158-68. doi: 10.1128/JVI.01028-13

9. Wu H, Zhao X, Wang F, Jiang Q, Shi L, Gong M, et al. Mouse Testicular Cell Type-Specific Antiviral Response against Mumps Virus Replication. Front Immunol (2017) 8:117. doi: 10.3389/fimmu.2017.00117

10. Jiang Q, Wang F, Shi L, Zhao X, Gong M, Liu W, et al. C-X-C motif chemokine ligand 10 produced by mouse Sertoli cells in response to mumps virus infection induces male germ cell apoptosis. Cell Death Dis (2017) 8: e3146. doi: 10.1038/cddis.2017.560

11. Wu H, Shi L, Wang Q, Cheng L, Zhao X, Chen Q, et al. Mumps virus-induced innate immune responses in mouse Sertoli and Leydig cells. Sci Rep (2016) 6:19507. doi: 10.1038/srep19507

12. Rubin S, Eckhaus M, Rennick LJ, Bamford CG, Duprex WP. Molecular biology, pathogenesis and pathology of mumps virus. J Pathol (2015) 235:242-52. doi: 10.1002/path.4445

13. Jin L, Orvell C, Myers R, Rota PA, Nakayama T, Forcic D, et al. Genomic diversity of mumps virus and global distribution of the 12 genotypes. Rev Med Virol (2015) 25:85-101. doi: 10.1002/rmv.1819 understanding of these questions would help in the development of preventative and therapeutic approaches for mumps orchitis and male infertility.

\section{AUTHOR CONTRIBUTIONS}

DH and HW designed the concept and wrote the manuscript. DT and FW collected materials and prepared figures. All authors contributed to the article and approved the submitted version.

\section{FUNDING}

This work was supported by grants from the National Key R\&D program of China (Nos. 2018YFC1003900 and 2016YFA0101001), and the National Natural Science Foundation of China (Nos. 81701430 and 82071633).
14. Johansson B, Tecle T, Orvell C. Proposed criteria for classification of new genotypes of mumps virus. Scand J Infect Dis (2002) 34:355-7. doi: 10.1080/ 00365540110080043

15. Galazka AM, Robertson SE, Kraigher A. Mumps and mumps vaccine: a global review. Bull World Health Organ (1999) 77:3-14. doi: 10.1007/bf02727158

16. Edmunds WJ, Gay NJ, Kretzschmar M, Pebody RG, Wachmann H. Network EPES-e. The pre-vaccination epidemiology of measles, mumps and rubella in Europe: implications for modelling studies. Epidemiol Infect (2000) 125:635-50. doi: $10.1017 / \mathrm{s} 0950268800004672$

17. Vandermeulen C, Roelants M, Vermoere M, Roseeuw K, Goubau P, Hoppenbrouwers K. Outbreak of mumps in a vaccinated child population: a question of vaccine failure? Vaccine (2004) 22:2713-6. doi: 10.1016/ j.vaccine.2004.02.001

18. Westphal DW, Eastwood A, Levy A, Davies J, Huppatz C, Gilles M, et al. A protracted mumps outbreak in Western Australia despite high vaccine coverage: a population-based surveillance study. Lancet Infect Diseases (2019) 19:177-84. doi: 10.1016/s1473-3099(18)30498-5

19. Qin W, Wang Y, Yang T, Xu XK, Meng XM, Zhao CJ, et al. Outbreak of mumps in a student population with high vaccination coverage in China: time for two-dose vaccination. Hum Vaccin Immunother (2019) 15:2106-11. doi: 10.1080/21645515.2019.1581526

20. Ma R, Lu L, Zhou T, Pan J, Chen M, Pang X. Mumps disease in Beijing in the era of two-dose vaccination policy, 2005-2016. Vaccine (2018) 36:2589-95. doi: 10.1016/j.vaccine.2018.03.074

21. Beleni AI, Borgmann S. Mumps in the Vaccination Age: Global Epidemiology and the Situation in Germany. Int J Environ Res Public Health (2018) 15:1618. doi: 10.3390/ijerph15081618

22. Willocks LJ, Guerendiain D, Austin HI, Morrison KE, Cameron RL, Templeton KE, et al. An outbreak of mumps with genetic strain variation in a highly vaccinated student population in Scotland. Epidemiol Infect (2017) 145:3219-25. doi: 10.1017/S0950268817002102

23. Patel LN, Arciuolo RJ, Fu J, Giancotti FR, Zucker JR, Rakeman JL, et al. Mumps Outbreak Among a Highly Vaccinated University Community-New York City, January-April 2014. Clin Infect Dis (2017) 64:408-12. doi: 10.1093/ cid/ciw762

24. Havlickova M, Limberkova R, Smiskova D, Herrmannova K, Jirincova $H$, Novakova L, et al. Mumps in the Czech Republic in 2013: Clinical Characteristics, Mumps Virus Genotyping, and Epidemiological Links. Cent Eur J Public Health (2016) 24:22-8. doi: 10.21101/cejph.a4512

25. Nedeljkovic J, Kovacevic-Jovanovic V, Milosevic V, Seguljev Z, Petrovic V, Muller CP, et al. A Mumps Outbreak in Vojvodina, Serbia, in 2012 Underlines the Need for Additional Vaccination Opportunities for Young Adults. PloS One (2015) 10:e0139815. doi: 10.1371/journal.pone.0139815 
26. Sane J, Gouma S, Koopmans M, de Melker H, Swaan C, van Binnendijk R, et al. Epidemic of mumps among vaccinated persons, The Netherlands, 20092012. Emerg Infect Dis (2014) 20:643-8. doi: 10.3201/eid2004.131681

27. Gilliland SM, Jenkins A, Parker L, Somdach N, Pattamadilok S, Incomserb P, et al. Vaccine-related mumps infections in Thailand and the identification of a novel mutation in the mumps fusion protein. Biologicals (2013) 41:84-7. doi: 10.1016/j.biologicals.2012.09.007

28. Barskey AE, Schulte C, Rosen JB, Handschur EF, Rausch-Phung E, Doll MK, et al. Mumps outbreak in Orthodox Jewish communities in the United States. N Engl J Med (2012) 367:1704-13. doi: 10.1056/NEJMoa1202865

29. Roberts C, Porter-Jones G, Crocker J, Hart J. Mumps outbreak on the island of Anglesey, North Wales, December 2008-January 2009. Euro Surveill (2009) 14:19109. doi: 10.2807/ese.14.05.19109-en

30. Cortese MM, Jordan HT, Curns AT, Quinlan PA, Ens KA, Denning PM, et al. Mumps vaccine performance among university students during a mumps outbreak. Clin Infect Dis (2008) 46:1172-80. doi: 10.1086/529141

31. Castilla J, Garcia Cenoz M, Barricarte A, Irisarri F, Nunez-Cordoba JM, Barricarte A. Mumps outbreak in Navarre region, Spain, 2006-2007. Euro Surveill (2007) 12:E070215.070211. doi: 10.2807/esw.12.07.03139-en

32. Zheng J, Zhou Y, Wang H, Liang X. The role of the China Experts Advisory Committee on Immunization Program. Vaccine (2010) 28 Suppl 1:A84-7. doi: 10.1016/j.vaccine.2010.02.039

33. Davis NF, McGuire BB, Mahon JA, Smyth AE, O’Malley KJ, Fitzpatrick JM. The increasing incidence of mumps orchitis: a comprehensive review. BJU Int (2010) 105:1060-5. doi: 10.1111/j.1464-410X.2009.09148.x

34. Centers for Disease Control and Prevention (CDC). Mumps epidemic-Iowa, 2006. MMWR Morb Mortal Wkly Rep (2006) 55:366-8.

35. Tae BS, Ham BK, Kim JH, Park JY, Bae JH. Clinical features of mumps orchitis in vaccinated postpubertal males: a single-center series of 62 patients. Korean J Urol (2012) 53:865-9. doi: 10.4111/kju.2012.53.12.865

36. A retrospective survey of the complications of mumps. J R Coll Gen Pract (1974) 24:552-6.

37. Bartak V. Sperm count, morphology and motility after unilateral mumps orchitis. J Reprod Fertil (1973) 32:491-4. doi: 10.1530/jrf.0.0320491

38. Clifford V, Wadsley J, Jenner B, Buttery JP. Mumps vaccine associated orchitis: Evidence supporting a potential immune-mediated mechanism. Vaccine (2010) 28:2671-3. doi: 10.1016/j.vaccine.2010.01.007

39. Kanda T, Mochida J, Takada S, Hori Y, Yamaguchi K, Takahashi S. Case of mumps orchitis after vaccination. Int J Urol (2014) 21:426-8. doi: 10.1111/ iju.12305

40. Abdelbaky AM, Channappa DB, Islam S. Unilateral epididymo-orchitis: a rare complication of MMR vaccine. Ann R Coll Surg Engl (2008) 90:336-7. doi: 10.1308/003588408X285694

41. Suzuki M, Takizawa A, Furuta A, Yanada S, Iwamuro S, Tashiro K. A case of orchitis following vaccination with freeze-dried live attenuated mumps vaccine. Nihon Hinyokika Gakkai Zasshi (2002) 93:577-9. doi: 10.5980/ jpnjurol1989.93.577

42. Wharton IP, Chaudhry AH, French ME. A case of mumps epididymitis. Lancet (2006) 367:702. doi: 10.1016/S0140-6736(06)68274-3

43. Tarantino L, Giorgio A, de Stefano G, Farella N. Echo color Doppler findings in postpubertal mumps epididymo-orchitis. J Ultrasound Med (2001) 20:1189-95. doi: 10.7863/jum.2001.20.11.1189

44. Park SJ, Kim HC, Lim JW, Moon SK, Ahn SE. Distribution of Epididymal Involvement in Mumps Epididymo-orchitis. J Ultrasound Med (2015) 34:1083-9. doi: 10.7863/ultra.34.6.1083

45. Yang DM, Kim SH, Kim HN, Kang JH, Seo TS, Hwang HY, et al. Differential diagnosis of focal epididymal lesions with gray scale sonographic, color Doppler sonographic, and clinical features. J Ultrasound Med (2003) 22:135-42; quiz 143-134. doi: 10.7863/jum.2003.22.2.135

46. Adamopoulos DA, Lawrence DM, Vassilopoulos P, Contoyiannis PA, Swyer GI. Pituitary-testicular interrelationships in mumps orchitis and other viral infections. Br Med J (1978) 1:1177-80. doi: 10.1136/bmj.1.6121.1177

47. Choi HI, Yang DM, Kim HC, Kim SW, Jeong HS, Moon SK, et al. Testicular atrophy after mumps orchitis: ultrasonographic findings. Ultrasonography (2020) 39:266-71. doi: 10.14366/usg.19097

48. Basekim CC, Kizilkaya E, Pekkafali Z, Baykal KV, Karsli AF. Mumps epididymo-orchitis: sonography and color Doppler sonographic findings. Abdom Imaging (2000) 25:322-5. doi: 10.1007/s002610000039
49. Krause CH, Molyneaux PJ, Ho-Yen DO, McIntyre P, Carman WF, Templeton KE. Comparison of mumps-IgM ELISAs in acute infection. J Clin Virol (2007) 38:153-6. doi: 10.1016/j.jcv.2006.10.010

50. Jalal H, Bahadur G, Knowles W, Jin L, Brink N. Mumps epididymo-orchitis with prolonged detection of virus in semen and the development of antisperm antibodies. J Med Virol (2004) 73:147-50. doi: 10.1002/jmv.10544

51. Casella R, Leibundgut B, Lehmann K, Gasser TC. Mumps orchitis: report of a mini-epidemic. J Urol (1997) 158:2158-61. doi: 10.1016/s0022-5347(01) 68186-2

52. Erpenbach KH. Systemic treatment with interferon-alpha 2B: an effective method to prevent sterility after bilateral mumps orchitis. J Urol (1991) 146:54-6. doi: 10.1016/s0022-5347(17)37713-3

53. Yeniyol CO, Sorguc S, Minareci S, Ayder AR. Role of interferon-alpha-2B in prevention of testicular atrophy with unilateral mumps orchitis. Urology (2000) 55:931-3. doi: 10.1016/s0090-4295(00)00491-x

54. Rothlin CV, Ghosh S, Zuniga EI, Oldstone MB, Lemke G. TAM receptors are pleiotropic inhibitors of the innate immune response. Cell (2007) 131:112436. doi: 10.1016/j.cell.2007.10.034

55. Fenner JE, Starr R, Cornish AL, Zhang JG, Metcalf D, Schreiber RD, et al. Suppressor of cytokine signaling 1 regulates the immune response to infection by a unique inhibition of type I interferon activity. Nat Immunol (2006) 7:33-9. doi: $10.1038 /$ ni1287

56. Piganis RA, De Weerd NA, Gould JA, Schindler CW, Mansell A, Nicholson SE, et al. Suppressor of cytokine signaling (SOCS) 1 inhibits type I interferon (IFN) signaling via the interferon alpha receptor (IFNAR1)-associated tyrosine kinase Tyk2. J Biol Chem (2011) 286:33811-8. doi: 10.1074/ jbc.M111.270207

57. Bjorvatn B. Mumps virus recovered from testicles by fine-needle aspiration biopsy in cases of mumps orchitis. Scand J Infect Dis (1973) 5:3-5. doi: 10.3109/inf.1973.5.issue-1.02

58. Weis W, Brown JH, Cusack S, Paulson JC, Skehel JJ, Wiley DC. Structure of the influenza virus haemagglutinin complexed with its receptor, sialic acid. Nature (1988) 333:426-31. doi: 10.1038/333426a0

59. Li W, Hulswit RJG, Widjaja I, Raj VS, McBride R, Peng W, et al. Identification of sialic acid-binding function for the Middle East respiratory syndrome coronavirus spike glycoprotein. Proc Natl Acad Sci U S A (2017) 114:E8508-17. doi: 10.1073/ pnas. 1712592114

60. Tan CW, Huan Hor CH, Kwek SS, Tee HK, Sam IC, Goh ELK, et al. Cell surface alpha2,3-linked sialic acid facilitates Zika virus internalization. Emerg Microbes Infect (2019) 8:426-37. doi: 10.1080/22221751.2019.1590130

61. Kubota M, Takeuchi K, Watanabe S, Ohno S, Matsuoka R, Kohda D, et al. Trisaccharide containing alpha2,3-linked sialic acid is a receptor for mumps virus. Proc Natl Acad Sci U S A (2016) 113:11579-84. doi: 10.1073/ pnas. 1608383113

62. Kubota M, Okabe I, Nakakita SI, Ueo A, Shirogane Y, Yanagi Y, et al. Disruption of the Dimer-Dimer Interaction of the Mumps Virus Attachment Protein Head Domain, Aided by an Anion Located at the Interface, Compromises Membrane Fusion Triggering. J Virol (2020) 94:e01732-19. doi: 10.1128/JVI.01732-19

63. Wang F, Chen R, Jiang Q, Wu H, Gong M, Liu W, et al. Roles of Sialic Acid, AXL, and MER Receptor Tyrosine Kinases in Mumps Virus Infection of Mouse Sertoli and Leydig Cells. Front Microbiol (2020) 11:1292. doi: 10.3389/ fmicb.2020.01292

64. Kubota M, Matsuoka R, Suzuki T, Yonekura K, Yanagi Y, Hashiguchi T. Molecular Mechanism of the Flexible Glycan Receptor Recognition by Mumps Virus. J Virol (2019) 93:e00344-19. doi: 10.1128/JVI.00344-19

65. Deng T, Chen Q, Han D. The roles of TAM receptor tyrosine kinases in the mammalian testis and immunoprivileged sites. Front Biosci (Landmark Ed) (2016) 21:316-27. doi: 10.2741/4390

66. Bhattacharyya S, Zagorska A, Lew ED, Shrestha B, Rothlin CV, Naughton J, et al. Enveloped viruses disable innate immune responses in dendritic cells by direct activation of TAM receptors. Cell Host Microbe (2013) 14:136-47. doi: 10.1016/j.chom.2013.07.005

67. Shimojima M, Takada A, Ebihara H, Neumann G, Fujioka K, Irimura T, et al. Tyro3 family-mediated cell entry of Ebola and Marburg viruses. J Virol (2006) 80:10109-16. doi: 10.1128/JVI.01157-06

68. Shibata T, Habiel DM, Coelho AL, Kunkel SL, Lukacs NW, Hogaboam CM. Axl receptor blockade ameliorates pulmonary pathology resulting from 
primary viral infection and viral exacerbation of asthma. J Immunol (2014) 192:3569-81. doi: 10.4049/jimmunol.1302766

69. Richard AS, Shim BS, Kwon YC, Zhang R, Otsuka Y, Schmitt K, et al. AXLdependent infection of human fetal endothelial cells distinguishes Zika virus from other pathogenic flaviviruses. Proc Natl Acad Sci U S A (2017) 114:20249. doi: 10.1073/pnas.1620558114

70. Wang H, Chen Y, Ge Y, Ma P, Ma Q, Ma J, et al. Immunoexpression of Tyro 3 family receptors-Tyro 3, Axl, and Mer-and their ligand Gas6 in postnatal developing mouse testis. J Histochem Cytochem (2005) 53:1355-64. doi: 10.1369/jhc.5A6637.2005

71. Pickar A, Xu P, Elson A, Zengel J, Sauder C, Rubin S, et al. Establishing a small animal model for evaluating protective immunity against mumps virus. PloS One (2017) 12:e0174444. doi: 10.1371/journal.pone.0174444

72. Wang XX, Ying P, Diao F, Wang Q, Ye D, Jiang C, et al. Altered protein prenylation in Sertoli cells is associated with adult infertility resulting from childhood mumps infection. J Exp Med (2013) 210:1559-74. doi: 10.1084/ jem.20121806

73. Sadler AJ, Williams BR. Interferon-inducible antiviral effectors. Nat Rev Immunol (2008) 8:559-68. doi: 10.1038/nri2314

74. Apari P, de Sousa JD, Muller V. Why sexually transmitted infections tend to cause infertility: an evolutionary hypothesis. PloS Pathog (2014) 10:e1004111. doi: 10.1371/journal.ppat.1004111

75. Kumar H, Kawai T, Akira S. Pathogen recognition by the innate immune system. Int Rev Immunol (2011) 30:16-34. doi: 10.3109/08830185.2010.529976

76. Guazzone VA, Jacobo P, Theas MS, Lustig L. Cytokines and chemokines in testicular inflammation: A brief review. Microsc Res Tech (2009) 72:620-8. doi: 10.1002/jemt.20704

77. Wileman T. Autophagy as a defence against intracellular pathogens. Essays Biochem (2013) 55:153-63. doi: 10.1042/bse0550153

78. Spencer JV, Religa P, Lehmann MH. Editorial: Cytokine-Mediated Organ Dysfunction and Tissue Damage Induced by Viruses. Front Immunol (2020) 11:2. doi: 10.3389/fimmu.2020.00002

79. Diemer T, Hales DB, Weidner W. Immune-endocrine interactions and Leydig cell function: the role of cytokines. Andrologia (2003) 35:55-63. doi: 10.1046/ j.1439-0272.2003.00537.x

80. Suh JH, Gong EY, Hong CY, Park E, Ahn RS, Park KS, et al. Reduced testicular steroidogenesis in tumor necrosis factor-alpha knockout mice. J Steroid Biochem Mol Biol (2008) 112:117-21. doi: 10.1016/j.jsbmb.2008.09.003

81. Wang F, Liu W, Jiang Q, Gong M, Chen R, Wu H, et al. Lipopolysaccharideinduced testicular dysfunction and epididymitis in mice: a critical role of tumor necrosis factor alphadagger. Biol Reprod (2019) 100:849-61. doi: 10.1093/biolre/ioy235

82. Theas MS, Rival C, Jarazo-Dietrich S, Jacobo P, Guazzone VA, Lustig L. Tumour necrosis factor-alpha released by testicular macrophages induces apoptosis of germ cells in autoimmune orchitis. Hum Reprod (2008) 23:186572. doi: $10.1093 /$ humrep/den 240

83. Hughes EG. The effectiveness of ovulation induction and intrauterine insemination in the treatment of persistent infertility: a meta-analysis. Hum Reprod (1997) 12:1865-72. doi: 10.1093/humrep/12.9.1865

84. Siu MK, Lee WM, Cheng CY. The interplay of collagen IV, tumor necrosis factor-alpha, gelatinase B (matrix metalloprotease-9), and tissue inhibitor of metalloproteases-1 in the basal lamina regulates Sertoli cell-tight junction dynamics in the rat testis. Endocrinology (2003) 144:371-87. doi: 10.1210/ en.2002-220786

85. Siemann DN, Strange DP, Maharaj PN, Shi PY, Verma S. Zika Virus Infects Human Sertoli Cells and Modulates the Integrity of the In Vitro Blood-Testis Barrier Model. J Virol (2017) 91:e00623-17. doi: 10.1128/JVI.00623-17

86. Yule TD, Montoya GD, Russell LD, Williams TM, Tung KS. Autoantigenic germ cells exist outside the blood testis barrier. J Immunol (1988) 141:1161-7.

87. Liu M, Guo S, Hibbert JM, Jain V, Singh N, Wilson NO, et al. CXCL10/IP-10 in infectious diseases pathogenesis and potential therapeutic implications. Cytokine Growth Factor Rev (2011) 22:121-30. doi: 10.1016/j.cytogfr. 2011.06.001

88. Krause KK, Azouz F, Shin OS, Kumar M. Understanding the Pathogenesis of Zika Virus Infection Using Animal Models. Immune Netw (2017) 17:287-97. doi: 10.4110/in.2017.17.5.287

89. Li N, Wang T, Han D. Structural, cellular and molecular aspects of immune privilege in the testis. Front Immunol (2012) 3:152. doi: 10.3389/ fimmu.2012.00152

Conflict of Interest: The authors declare that the research was conducted in the absence of any commercial or financial relationships that could be construed as a potential conflict of interest.

Copyright (c) $2021 \mathrm{Wu}$, Wang, Tang and Han. This is an open-access article distributed under the terms of the Creative Commons Attribution License (CC BY). The use, distribution or reproduction in other forums is permitted, provided the original author(s) and the copyright owner(s) are credited and that the original publication in this journal is cited, in accordance with accepted academic practice. No use, distribution or reproduction is permitted which does not comply with these terms. 